\title{
Cellulosic Ethanol Production by Recombinant Cellulolytic Bacteria Harbouring pdc and adh II Genes of Zymomonas mobilis
}

\author{
P. Sobana Piriya, P. Thirumalai Vasan, V. S. Padma, U. Vidhyadevi, \\ K. Archana, and S. John Vennison \\ Department of Biotechnology, Anna University of Technology, Tamil Nadu, Tiruchirappalli 620024, India \\ Correspondence should be addressed to S. John Vennison, johnvennison36@gmail.com
}

Received 26 March 2012; Accepted 12 June 2012

Academic Editor: Triantafyllos Roukas

Copyright ( $) 2012$ P. Sobana Piriya et al. This is an open access article distributed under the Creative Commons Attribution License, which permits unrestricted use, distribution, and reproduction in any medium, provided the original work is properly cited.

\begin{abstract}
The ethanol fermenting genes such as pyruvate decarboxylase $(p d c)$ and alcohol dehydrogenase II (adh II) were cloned from Zymomonas mobilis and transformed into three different cellulolytic bacteria, namely Enterobacter cloacae JV, Proteus mirabilis JV and Erwinia chrysanthemi and their cellulosic ethanol production capability was studied. Recombinant E. cloacae JV was found to produce $4.5 \%$ and $3.5 \%(\mathrm{v} / \mathrm{v})$ ethanol, respectively, when $\mathrm{CMC}$ and $4 \% \mathrm{NaOH}$ pretreated bagasse were used as substrates, whereas recombinant $P$. mirabilis and $E$. chrysanthemi with the same substrates could only produce $4 \%, 3.5 \%, 1 \%$, and $1.5 \%$ of ethanol, respectively. The recombinant $E$. cloacae strain produced twofold higher percentage of ethanol than the wild type. The recombinant E. cloacae strain could be improved further by increasing its ethanol tolerance capability through media optimization and also by combining multigene cellulase expression for enhancing ethanol production from various types of lignocellulosic biomass so that it can be used for industrial level ethanol production.
\end{abstract}

\section{Introduction}

The conversion of plant cellulose biomass to fuel ethanol by microbial fermentation is the priority area of research, and the use of industrially suited microorganisms for the cost-effective biofuel production is the major technical challenge. Cellulosic ethanol would reduce our petroleum dependency, as ethanol is produced from the inexpensive and plentiful feed stocks. Efficient conversion of biomass to ethanol requires development of microorganisms capable of fermenting a wide range of carbohydrates and tolerating high concentrations of ethanol [1]. Metabolic engineering of microorganisms to utilize cellulose will be vital for improving the prospects of significant cellulosic ethanol production. Several Gram-negative bacteria such as Escherichia coli, Klebsiella oxytoca, and Zymomonas mobilis have been engineered for ethanol production [2-5].

Enteric bacteria normally produce less ethanol, because of their poor efficiency in converting pyruvate to ethanol.
A suitable ethanologenic and cellulose-producing bacteria could be developed by transferring genes that encode the ethanol-fermenting enzymes [6]. Z. mobilis is one of the best ethanol producers which produces ethanol in the EntnerDoudoroff (ED) pathway, that is, homoethanol fermentation pathway with the help of two essential enzymes such as pyruvate decarboxylase (PDC) and alcohol dehydrogenase (ADH) encoded by $p d c$ and $a d h$ II genes, respectively. PDC catalyzes the nonoxidative decarboxylation of pyruvate to produce acetaldehyde and carbon dioxide, whereas $\mathrm{ADH}$ catalyzes the reduction of acetaldehyde to ethanol during fermentation [7-9]. These two enzymes (both PDC and $\mathrm{ADH}$ ) are sufficient to convert intracellular pool of pyruvate and NADH to ethanol [10].

The transfer of ethanol-fermenting genes ( $p d c$ and $a d h$ ) from Z. mobilis to cellulolytic bacteria could definitely improve their ethanol productivity by converting pyruvate completely to ethanol. The research on the construction of recombinant ethanol fermenting bacteria by expressing 
both the $p d c$ and adh II genes was originally done by Ingram et al. [9] in E. coli to change the ethanol production ability by fermenting all sugars in the biomass. Similarly, recombinant Erwinia sp. [11] and Klebsiella oxytoca M5A1 [2] were developed to improve the ethanol production from xylose and glucose. Recombinant Gram-negative E. coli KO11 [1] and Gram-positive Clostridium cellulolyticum [12] were constructed to produce ethanol from acid hydrolysates of hemicellulose and lignocellulosic biomass, respectively. Though these reports did explain the cloning of $p d c$ and adh genes, but the subsequent usage of the cloned genes for ethanol production was not explained clearly. The formation of additional byproducts during fermentation and tolerance to the produced ethanol are the major limitations observed in these studies. The bioethanol production from cellulosic biomass in cellulolytic microorganisms can be improved by introducing ethanol-fermenting genes under the control of an appropriate promoter [9].

In the present study, the ethanol fermenting genes such as $p d c$ and $a d h$ II were cloned from $Z$. mobilis and introduced into three facultative anaerobic, Gram-negative cellulolytic bacteria. The cellulosic ethanol production capability of these recombinant strains was determined through simultaneous saccharification and fermentation (SSF) process using carboxymethyl cellulose and alkali-pretreated bagasse as substrates.

\section{Methods}

2.1. Bacterial Strains, Plasmids, and Growth Conditions. Z. mobilis subsp. mobilis MTCC 92 [5] and E. coli DH5 $\alpha$ were obtained from the Microbial Type Culture Collection (MTCC), Chandigarh, India. E. coli harboring pUC18 amp $p^{\mathrm{R}}$, cloning vector, lac promoter, $(2.7 \mathrm{~kb})$ was obtained from Fermentas (USA). E. cloacae JV and P. mirabilis JV were isolated and characterized in our laboratory from the gut of termite (Heterotermes indicola) and silk worm (Bombyx mori), respectively. The $16 \mathrm{~s}$ rDNA sequence of the organisms was submitted in National Center for Biotechnology Information (NCBI), E. cloacae JV (FJ 799063) and P. mirabilis JV (HQ231796). E. chrysanthemi was obtained from the National Institute of Agrobiological Sciences, Japan. $Z$. mobilis subsp. mobilis was grown on yeast extract medium supplemented with $20 \%$ glucose, $0.5 \%$ yeast extract, $0.1 \%$ ammonium sulphate, $0.1 \%$ potassium dihydrogen orthophosphate, and $0.05 \%$ magnesium chloride, $\mathrm{pH} 7$, at $30^{\circ} \mathrm{C}$ with agitation at $100 \mathrm{rpm}$. E. coli harbouring pUC18 was grown on Luria agar with ampicillin $(100 \mu \mathrm{g} / \mathrm{mL})$ under static condition at $37^{\circ} \mathrm{C}$ and E. chrysanthemi, E. cloacae JV, P. mirabilis JV, and E. coli DH5 $\alpha$ were also cultured on Luria agar.

2.2. Cloning of pdc and adh II Genes. Chromosomal DNA was isolated from $Z$. mobilis MTCC 92 as described by Sambrook and Russel [13] and the pUC18 plasmid DNA was isolated by alkaline lysis method [14]. Cloning of $p d c$ gene was carried out by restricting both the total genomic DNA $(20 \mu \mathrm{g})$ and plasmid DNA $(7 \mu \mathrm{g})$ with 10 units of EcoRI, 10 units of BamHI (Fermentas, USA), $2.5 \mu \mathrm{L}$ of restriction buffer, and $9.5 \mu \mathrm{L}$ of sterile distilled water to a total volume of $25 \mu \mathrm{L}$. The adh II gene cloning was done as described above using BamHI and HindIII enzymes. The reaction mixtures were incubated at $37^{\circ} \mathrm{C}$ for $2 \mathrm{~h}$. The restriction reaction was stopped by heating the reaction mixture at $65^{\circ} \mathrm{C}$ for $20 \mathrm{~min}$. The restricted and purified DNA samples were ligated by mixing $8 \mu \mathrm{g}$ of digested genomic DNA, $1 \mu \mathrm{g}$ of digested pUC18 plasmid DNA, $4 \mu \mathrm{L}$ of $\mathrm{T}_{4}$ DNA ligase buffer, and 5 units of $\mathrm{T}_{4}$ DNA ligase enzyme (Fermentas, USA) and incubated at $16^{\circ} \mathrm{C}$ for $16 \mathrm{~h}$ [13].

The ligated mix was transformed into competent $E$. coli $\mathrm{DH} 5 \alpha$ cells by $\mathrm{CaCl}_{2}$ method. The transformants were plated on Luria agar supplemented with ampicillin (50 mg/mL), IPTG $(40 \mathrm{mg} / \mathrm{mL})$, and X-gal $(20 \mathrm{mg} / \mathrm{mL})$, the white-coloured recombinant clones were selected. The $p d c$ clones expressing pyruvate decarboxylase enzyme were further screened by plating the white colonies on Luria agar supplemented with $1 \%$ Schiff reagent, $50 \mathrm{mM}$ sodium pyruvate and ampicillin $(50 \mathrm{mg} / \mathrm{mL})$ whereas the adh clones were screened on Luria agar supplemented with 1\% Schiff reagent, $5 \%$ ethanol, and ampicillin $(50 \mathrm{mg} / \mathrm{mL})$ [15]. The clones showing intensive red colour on aldehyde indicator plates were selected as positive clones.

2.3. Cell Extracts Preparation. The $p d c$ and adh positive clones were grown in $100 \mathrm{~mL}$ Luria broth supplemented with ampicillin $(100 \mathrm{mg} / \mathrm{mL})$ for $18 \mathrm{~h}$ at $37^{\circ} \mathrm{C}$. After incubation, cells were harvested by centrifugation $(10,000 \mathrm{rpm}$, $5 \mathrm{~min}, 4^{\circ} \mathrm{C}$ ) and the cells were washed with $10 \mathrm{mM}$ Tris hydrochloride buffer ( $\mathrm{pH}$ 7.0) containing $1 \mathrm{mM}$ EDTA and resuspended in $10 \mathrm{~mL}$ of the same buffer. Lysozyme was added at a final concentration of $1 \mathrm{mg} / \mathrm{mL}$ and the mixture was incubated for $30 \mathrm{~min}$ at room temperature. Cells were lysed by sonication using a Bandelin sonicator (UW 2200) for three cycles at $40 \mathrm{~W}$ with $45 \mathrm{sec}$ intervals. Cell extracts were collected by centrifugation $\left(15,000 \mathrm{rpm}, 30 \mathrm{~min}, 4^{\circ} \mathrm{C}\right)$ and the supernatant was used as source of enzyme [16].

\section{Expression of $Z$. mobilis Genes in E. coli}

3.1. PDC Activity. PDC activity was measured in triplicate by monitoring the pyruvic acid-dependent oxidation of NADH with $\mathrm{ADH}$ as a coupling enzyme. The reaction mixture consisted of $2.7 \mathrm{~mL}$ of $200 \mathrm{mM}$ citrate buffer, $100 \mu \mathrm{L}$ of $1 \mathrm{M}$ sodium pyruvate, $50 \mu \mathrm{L}$ of $6.4 \mathrm{mM} \beta-\mathrm{NADH}$, and $100 \mu \mathrm{L}$ of cell extract. The reaction mixture was mixed and the assay was carried out at $25^{\circ} \mathrm{C}$. The enzyme activity was determined by measuring the conversion of $\mathrm{NADH}$ to $\mathrm{NAD}^{+}$at $340 \mathrm{~nm}$ using varian spectrophotometer. The decrease in absorbance value was recorded. The rate that is $\mathrm{rA} 340 \mathrm{~nm} / \mathrm{mL}$ was obtained using the maximum linear rate for both the test and the blank [17]. One unit of activity is defined as the amount of activity required for the conversion of $1 \mu \mathrm{mol}$ of NADH to $\mathrm{NAD}^{+}$per min.

3.2. ADH Activity. Assay of $\mathrm{ADH}$ was measured in triplicate by monitoring the ethanol-dependent reduction of NAD, in which the conversion of NAD to NADH was determinedspectrophotometrically. The reaction mixture containing 
$0.1 \mathrm{~mL}$ of $15 \mathrm{mM}$ NADP, $2.4 \mathrm{~mL}$ of $100 \mathrm{mM}$ Tris- $\mathrm{HCl}$, $0.3 \mathrm{~mL}$ of propane 2 -ol $(100 \%)$, and $0.2 \mathrm{~mL}$ of cell extract and incubated at $40^{\circ} \mathrm{C}$ for $5 \mathrm{~min}$. The alcohol-dependent reduction of $\mathrm{NAD}^{+}$using propane-2-ol was measured at $340 \mathrm{~nm}$ [18]. One unit of ADH activity is defined as the amount that reduces $1 \mu \mathrm{mol}$ of $\mathrm{NAD}^{+} / \mathrm{min}$.

Both enzyme activities were calculated using the following formula:

$$
\begin{aligned}
\text { Unit } / \mathrm{mL} \text { extract }= & \frac{\left(\Delta \mathrm{A}_{340 \mathrm{~nm}} / \mathrm{min} \text { test }-\Delta \mathrm{A}_{340 \mathrm{~nm}} / \mathrm{min} \text { blank }\right)}{(6.22)(\text { enzyme volume })} \\
& \times(\text { reaction volume }) \times \mathrm{DF} .
\end{aligned}
$$

6.22 is the millimolar extinction coefficient of $\beta$-NADH at $340 \mathrm{~nm}$ and DF is the dilution factor.

3.3. DNA Sequencing. The clones which showed higher $\mathrm{PDC}$ and $\mathrm{ADH}$ activity were selected for sequencing. The cycle sequencing reaction was performed using BigDye Terminator V3.1 Cycle Sequencing Kit containing AmpliTaq DNA polymerase (from Applied Biosystems, PN: 4337457). The sequencing reaction mix was prepared by adding $1 \mu \mathrm{L}$ of BigDye v3.1, $2 \mu \mathrm{L}$ of $5 \mathrm{x}$ sequencing buffer, and $1 \mu \mathrm{L}$ of $50 \%$ Dimethyl sulfoxide (DMSO). Four microlitres of sequencing reaction mixture, 4 Pico moles of primer $(2 \mu \mathrm{L})$, and sufficient amount of plasmid DNA were added. The constituted reaction was denatured at $95^{\circ} \mathrm{C}$ for $5 \mathrm{~min}$. Cycling began with denaturing at $95^{\circ} \mathrm{C}$ for $30 \mathrm{sec}$, annealing at $52^{\circ} \mathrm{C}$ for $30 \mathrm{sec}$, and extension for $4 \mathrm{~min}$ at $60^{\circ} \mathrm{C}$ and cycle repeated for 30 cycles in a MWG thermocycler. The reaction content was then purified on sephadex plate (Edge Biosystems) by centrifugation to remove unbound labeled, and unlabeled nucleotides and salts. The purified reaction product was loaded on to the 96 capillary ABI 3700 DNA analyzer and electrophoresis was carried out for $4 \mathrm{~h}$. The nucleotide sequences of both $p d c$ and $a d h$ II genes were analysed, confirmed, and submitted to the National Center for Biotechnology Information (NCBI).

3.4. Cloning of pdc and adh II Genes. Both $p d c$ and $a d h$ II genes were subcloned together by digesting pUC18-adh with BamHI and HindIII enzymes and eluted from the gel to ligate with BamHI- and HindIII-digested pUC18-pdc clone in such a way that the $a d h$ II fragment was at the downstream of $p d c$ gene. The ligated mix was transformed into competent $E$. coli DH5 $\alpha$ cells by calcium chloride method. The transformants having both ADH and PDC activity were screened further on selective aldehyde indicator plates, enzyme assays, and by restriction analysis [13].

3.5. Ethanol Tolerance Assay. Single colony of each cellulolytic bacteria such as E. chrysanthemi, E. cloacae JV, and P. mirabilis JV were inoculated separately in $5 \mathrm{~mL}$ of Luria broth and incubated at $37^{\circ} \mathrm{C}$ in a shaker at $200 \mathrm{rpm}$. Five hundred microlitres of the overnight cultures were subcultured to $50 \mathrm{~mL}$ Luria broth (supplemented with 0,2 , 4,6 , and $10 \%$ ethanol) in closed culture tubes to prevent ethanol volatilization and were incubated at $37^{\circ} \mathrm{C}$ on a rotary shaker with an aeration speed of $200 \mathrm{rpm}$ and the density of bacterial culture was measured at $600 \mathrm{~nm}$ [19].

3.6. Transformation of Cellulolytic Bacteria. The pUC18-pdcadh II plasmid was purified from E. coli and transformed into cellulolytic bacteria such as E. chrysanthemi, E. cloacae JV, and $P$. mirabilis JV by electroporation (single pulse at $6.25 \mathrm{KV}$ using $25 \mathrm{mF}$ capacitor at a resistance of $200 \mathrm{Ohm}$ in cooled $0.2 \mathrm{~cm}$ cuvette which contained $50 \mathrm{ng}$ of plasmid DNA, $40 \mu \mathrm{L}$ of P. mirabilis JV, E. cloacae JV, and E. chrysanthemi competent cells in separate cuvettes using Biorad electroporator). After electroporation, cells were incubated for one hour in SOC medium and then plated on selective agar supplemented with ampicillin $(100 \mu \mathrm{g} / \mathrm{mL})$ [20]. Those clones that developed intensive red color on aldehyde indicator plates were selected. The clones showing higher enzymatic activity were further confirmed by PDC/ADH assay.

3.7. Analysis of Plasmid Profile and Restriction Mapping. The transformants of cellulolytic bacteria were confirmed by analyzing their plasmid profile and by restriction analysis. The transformation of plasmid pUC18-pdc-adh into the cellulolytic bacteria was confirmed through horizontal slot lysis electrophoresis as described by Vennison [21]. The transformed colonies on agar plates were resuspended in protoplasting buffer $(15 \mu \mathrm{L})$ to a density of $10^{5}$ cell $/ \mathrm{mL}$. Bacterial cells were mixed thoroughly by vigorous vortexing. The mixtures were incubated at $37^{\circ} \mathrm{C}$ for $15 \mathrm{~min}$ for the formation of protoplasts. Agarose gel (0.7\%) was prepared with $1 X$ Tris-Boric acid-EDTA buffer with $0.05 \%$ SDS. The gel slots were preloaded with $20 \mu \mathrm{L}$ of lysis buffer and allowed to stand for $20 \mathrm{~min}$. Then $10 \mu \mathrm{L}$ of protoplast suspension was loaded into each slot and the electrophoresis was carried out initially with 50 volts and then to 100 volts till the completion of the run. After the completion of electrophoresis, the gel was stained with $0.05 \mu \mathrm{g} / \mathrm{mL}$ of ethidium bromide. The size of plasmids such as pUC18-pdc, pUC18-adh, and pUC18$p d c$-adh was determined by linearizing the plasmids with BamHI enzyme and electrophoresed on $0.7 \%$ of agarose gel along with the DNA molecular weight marker. The DNA bands were visualized under UV transilluminator and photographed using Alpha gel documentation system (USA).

3.8. Cellulosic Ethanol Production. Ethanol fermentation experiments were carried out independently with $0.6 \%$ carboxyl methyl cellulose and $1 \mathrm{~g}$ of $4 \% \mathrm{NaOH}$-treated bagasse [5] in the luria broth supplemented with $0.1 \%$ ammonium sulfate, $0.1 \%$ potassium dihydrogen orthophosphate, and $0.05 \%$ magnesium sulphate at $37^{\circ} \mathrm{C}$ and $\mathrm{pH} 7.0$ with an agitation speed of $150 \mathrm{rpm}$ agitation as described by Jeffers [22]. The fermentation was performed in a round bottom flask connected with an $U$-tube. The outlet was fitted with a test tube containing $\mathrm{Ca}(\mathrm{OH})_{2}$ to maintain anaerobic conditions and $\mathrm{pH}$ of the fermentation medium [23]. After $48 \mathrm{~h}$, the ethanol was distilled at $78.5^{\circ} \mathrm{C}$ and ethanol concentrations in the distillate were determined by potassium dichromate method [24]. 


\section{Results}

4.1. Cloning of pdc and adh II Genes and Their Expression in E. coli . Z. mobilis genes encoding PDC and ADH II enzymes were expressed in E. coli using a vector pUC18 (Figure 1) and the transformants expressing the gene were screened by red spots on aldehyde indicator plates supplemented with ampicillin $(100 \mathrm{mg} / \mathrm{mL})$. The PDC and ADH activity was further confirmed by direct spectrophoto metric assay of cell lysate (Figure 2). A PDC clone showed a higher activity of $0.6582(\mathrm{U} / \mathrm{mL})$ was named as pUC18- $p d c$, whereas an $\mathrm{ADH}$ clone showed an activity of $0.117(\mathrm{U} / \mathrm{mL})$ was named as pUC18-adh II. The experiment was repeated for six times and the enzyme activity data were statistically analyzed by Student's $t$-test by comparing the enzyme activity of the clone with control E. coli strain. The statistical analysis predicted that the calculated value for both enzyme activities was greater than the tabulated value $(10.1>2.36)$ at $P<$ 0.05 . These analyses showed that there was a significant difference between the enzyme activities of the clones and the control E. coli strain. The nucleotide sequences of both $p d c$ and $a d h$ II genes cloned from $Z$. mobilis were deposited in NCBI (the accession number for $p d c$ gene is HM235920 and for $a d h$ gene is HM235921). The $p d c$ gene sequence contained an open-reading frame of $1707 \mathrm{bp}$ and the adh II gene contained an open-reading frame of $1152 \mathrm{bp}$. Both $p d c$ and $a d h$ II gene sequences showed a maximum of $99 \%$ similarity when compared to the sequence of $p d c$ and $a d h$ II gene of $Z$. mobilis already available in NCBI (AB359062.1 and AB359063.1). These clones of $p d c$ and adh genes were found to contain insert DNA of 3 and $4 \mathrm{~kb}$, respectively (Figure 3).

4.2. Construction of pUC18-pdc-adh for Ethanol Production. The pUC18-adh II and pUC18-pdc were digested with the restriction enzymes BamHI and HindIII, ligated and transformed into E. coli. Clones expressing both $p d c$ and $a d h$ II genes grew poorly on Luria agar plates but grew at higher densities than the individual $p d c$ and $a d h$ II clone on agar plates supplemented with $2 \%$ glucose. The colony size and opacity had proven as useful markers for the identification of recombinants which harboured both alcohol dehydrogenase and pyruvate decarboxylase genes. Positive colonies appeared intensely red, whereas negative colonies ranging from white to medium shades of red on the aldehyde indicator plate. Among the 20 positive colonies, five intensively red colonies were selected and their intracellular enzyme activities were determined. The efficient clone with higher enzyme activity was designated as pUC18-pdc-adh and selected for further studies.

4.3. Ethanol Tolerance Assay. The ethanol tolerance assay of cellulolytic bacteria was carried out by culturing the bacterial strains in the luria broth supplemented with ethanol at different concentration $(0-10 \%)$ and the culture densities were measured at $600 \mathrm{~nm}$ (Figure 4). The turbidity of $E$. cloacae was clearly visible till $4 \%$, whereas the turbidity of the other strains was visible only till $2 \%$ of ethanol. The optical density of these cellulolytic bacteria in different concentration of ethanol medium revealed that the $E$. cloacae growth rate was decreased slowly till $4 \%$, but the growth rates of other strains were rapidly decreased at $1-2 \%$.

4.4. Transformation of pUC18-pdc-adh into Cellulolytic Bacteria. The pUC18-pdc-adh clone was transformed into E. chrysanthemi, E. cloacae JV, and P. mirabilis JV through electroporation. The transformants were selected on the aldehyde indicator plates supplemented with ampicillin. On agar medium, the recombinant ethanologenic clones were readily apparent as large, raised colonies. The efficient strains that are able to convert glucose to ethanol were recognized by the production of red spots on aldehyde indicator plates. Efficient clones from each cellulolytic strain with efficient enzyme activity were selected for cellulosic ethanol production. Plasmid DNA profile from all the three recombinant cellulolytic bacteria was examined through slot lysis electrophoresis which was found identical to that of pUC18-pdc-adh.

4.5. Fermentation of Cellulose to Ethanol. The optimum temperature and $\mathrm{pH}$ for the ethanol production was $37^{\circ} \mathrm{C}$ and 7.0. The fermentation was carried out under anaerobic conditions for $48 \mathrm{~h}$ with agitation of $150 \mathrm{rpm}$. The cellulosic ethanol production capability of recombinant cellulolytic bacteria harbouring both $p d c$ and $a d h$ II genes was studied with carboxymethyl cellulose and pretreated bagasse as substrates (Figure 5). The recombinant strains produced ethanol more rapidly and efficiently when compared to their respective parental strains. Recombinant E. chrysanthemi could produce ethanol from CMC and pretreated bagasse slightly higher than the wild type. The ethanol production by recombinant $P$. mirabilis from $4 \% \mathrm{NaOH}$-treated bagasse did not show any significant increase when compared to the wild type. The recombinant E. cloacae JV had shown twofold increase in ethanol production than the wild type. Among the recombinants E. cloacae JV harboring pUC18$p d c-a d h$, plasmid construct was identified as the best strain for ethanol production, with a maximum of $4.5 \%$ and 3.5\% of ethanol with carboxyl methyl cellulose and $4 \% \mathrm{NaOH}$ treated bagasse, respectively. Experiments were performed six times and statistical analyses of the data were performed using the Student's $t$-test. The statistical analyses showed a significant difference in the cellulosic ethanol production between the wild type E. cloacae and recombinant E. cloacae at $P<0.05$.

\section{Discussion}

Cellulosic ethanol production from lignocellulosic biomass is a globally developing technology. One of the major issues for cellulosic ethanol production is enzyme hydrolysis by the naturally available strains to convert cellulose to glucose. Developing a single strain for efficient cellulosic ethanol production is the technical challenge. The present work has taken up the challenge by improving the ethanol fermenting capabilities of cellulolytic 


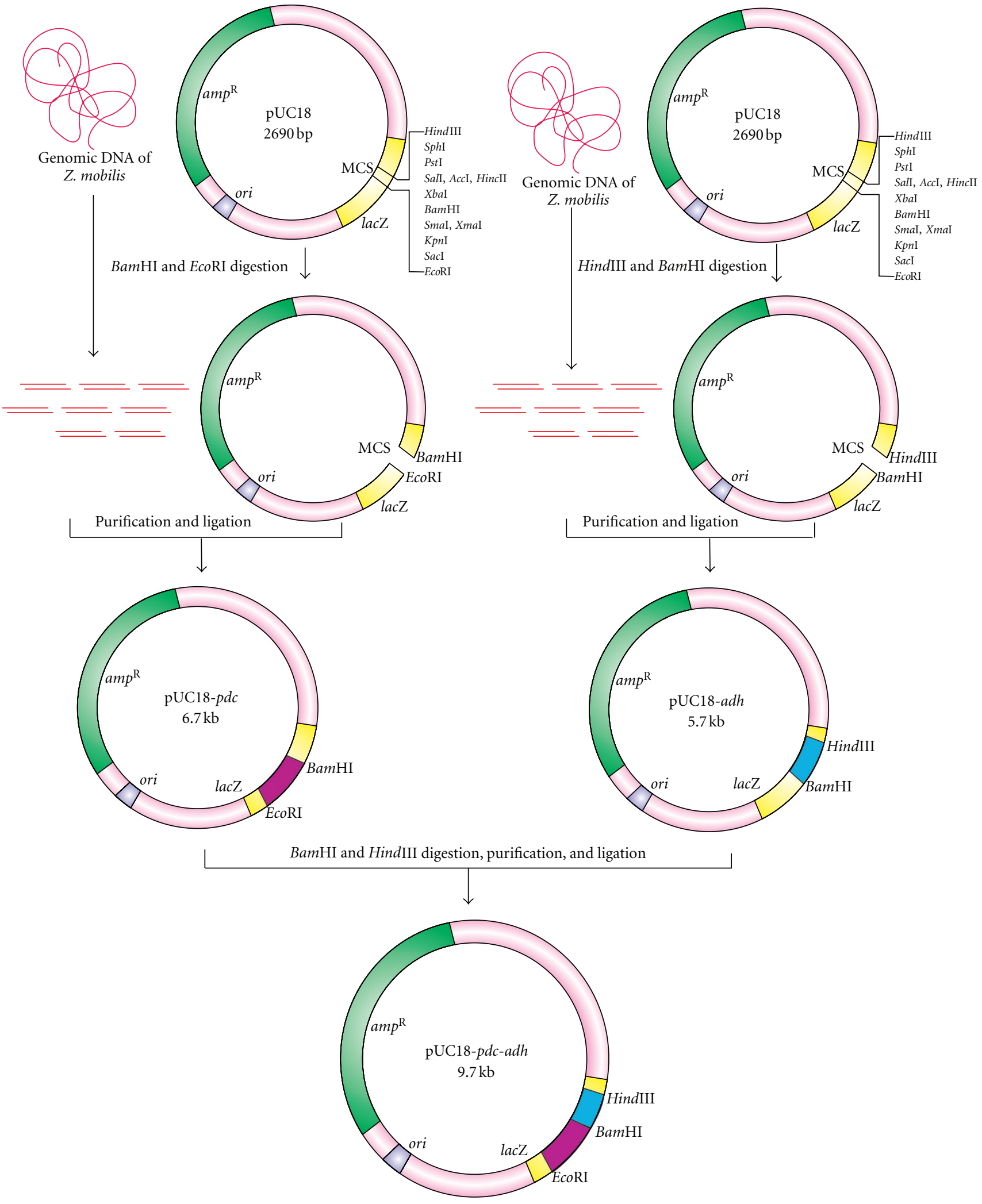

FIGURE 1: Cloning of $p d c$ and $a d h$ II genes in pUC18 plasmid. 


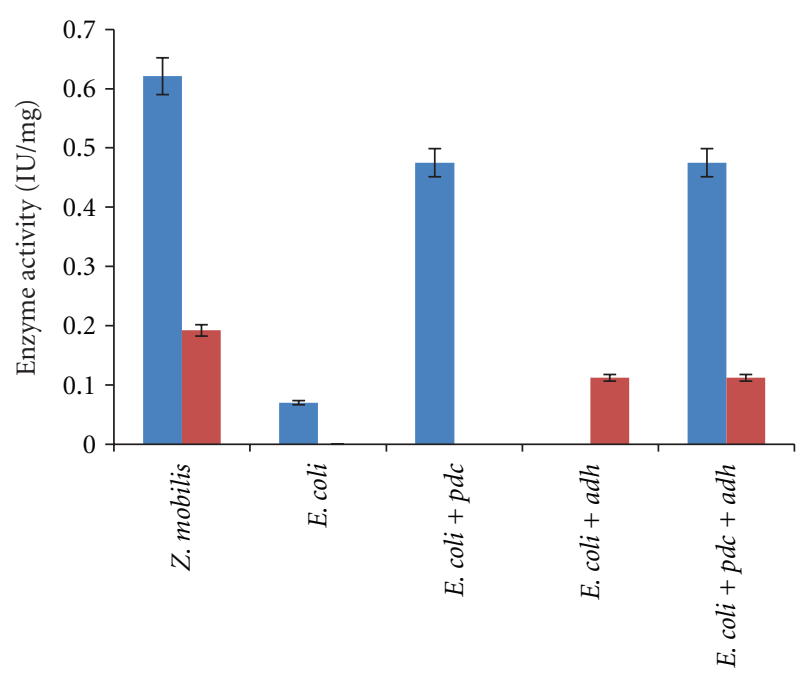

Microorganism

- PDC activity

- ADH activity

FIgUre 2: The intracellular PDC and ADH activities of the recombinant bacteria.

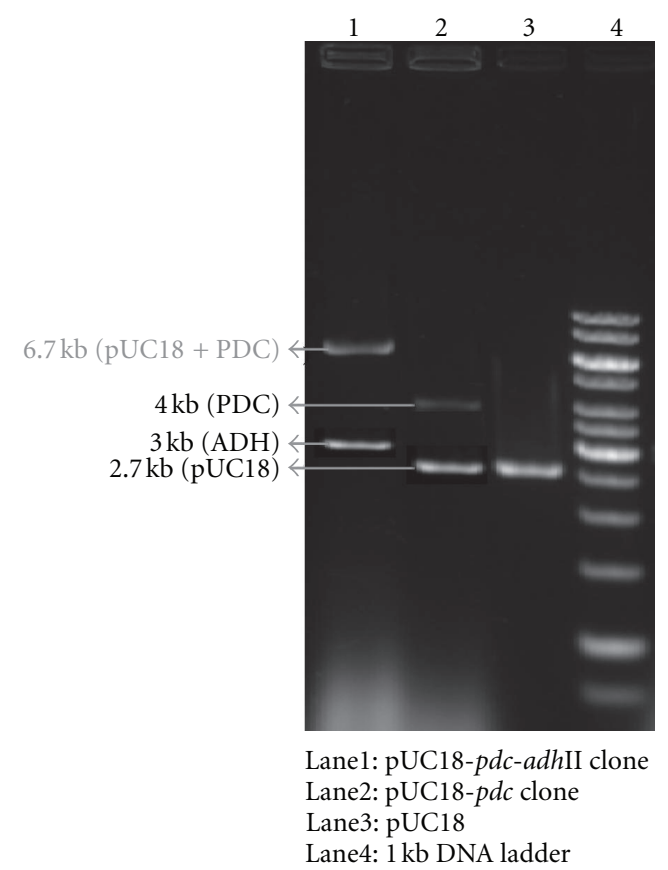

FIgURE 3: Restriction analysis of $p d c$ and $a d h$ II clones.

bacteria through cloning of $p d c$ and $a d h$ genes from Z. mobilis.

There are several reports on the construction of an artificial, pet operon, for the production of ethanol by combining both $p d c$ and $a d h \mathrm{II}$ genes. The first successfully constructed recombinant organism was E. coli KO11 which had the ability to ferment a wide spectrum of sugars but the ethanol yield was $4.3 \%$ from glucose as a substrate [9], but the cells could tolerate only $2 \%$ ethanol [25]. Other Gram-negative bacteria such as Klebsiella oxytoca and
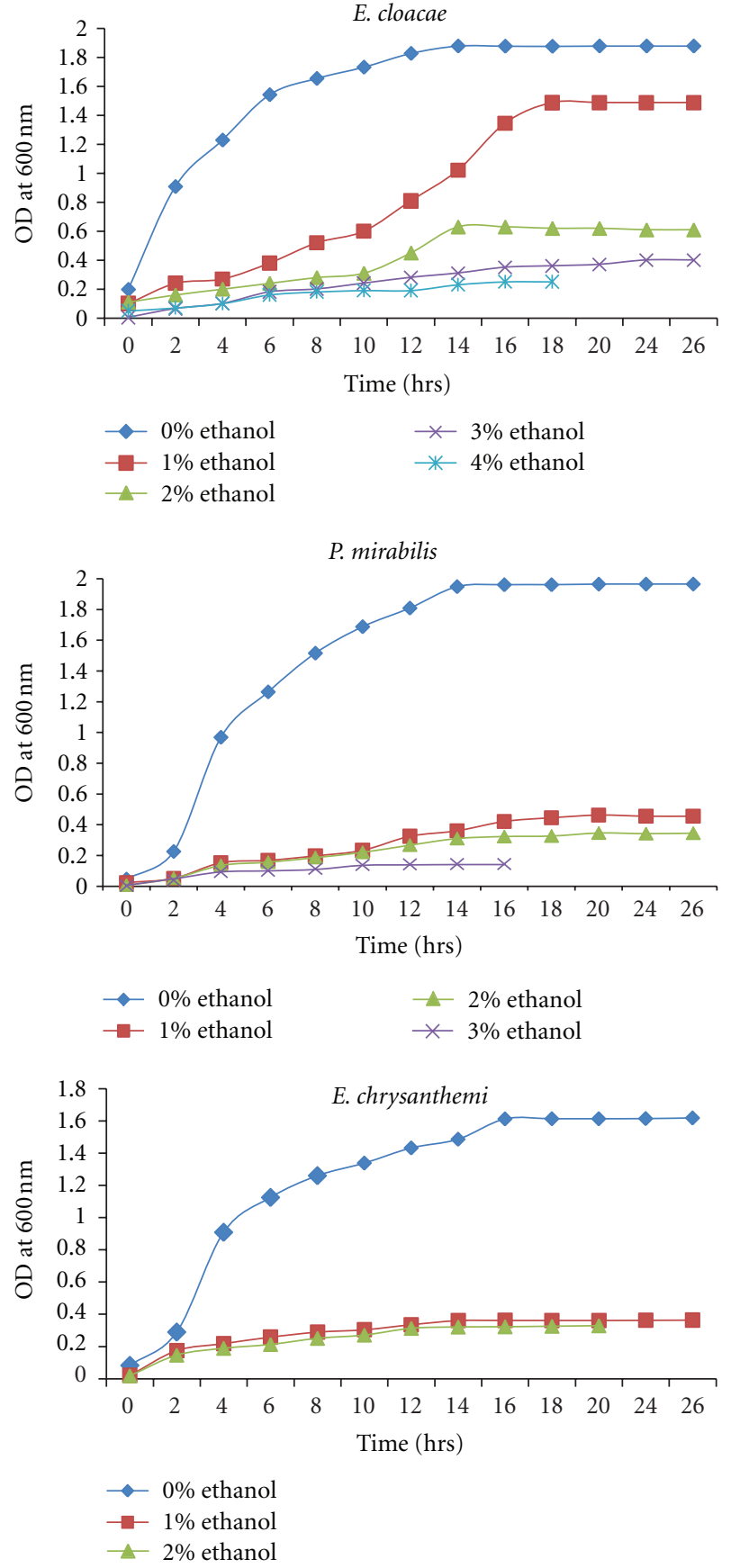

Figure 4: Ethanol tolerance assay of cellulolytic bacteria.

E. chrysanthemi were also transformed with pet operon but these strains have lower ethanol yield than E. coli KO11 [26]. The K. oxytoca was further improved to enhance the ethanol yield by overcoming its limitations, but the yield was increased to $40 \mathrm{~g} / \mathrm{L}$ using raw sugarcane but the process took 13 days time for the overall production [27]. The expression of this pet operon in other Gram-positive microorganisms also had shown very less ethanol yield [28]. The engineered cellulolytic bacterium, Clostridium cellulolyticum with $p d c$ and $a d h$ II of $Z$. mobilis showed $150 \%$ increase in cellulose consumption and the concentrations of acetate and ethanol 


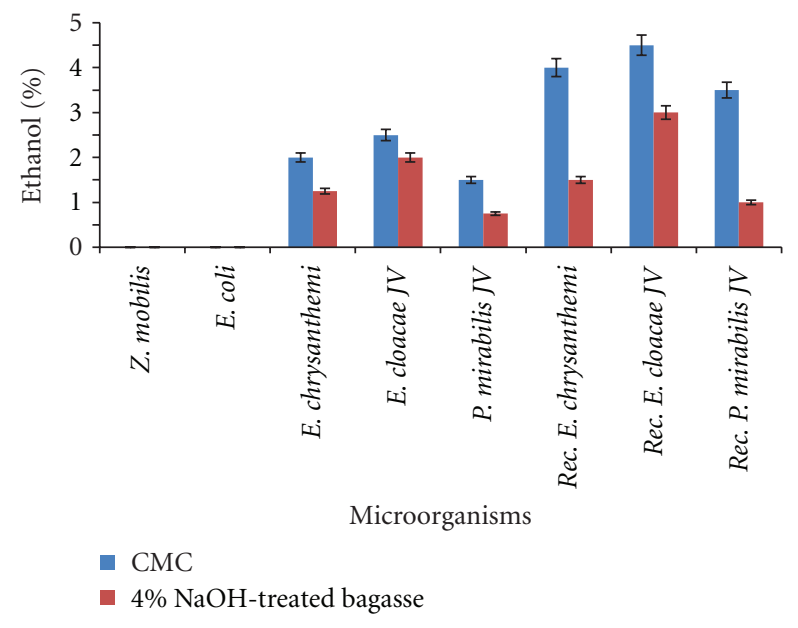

Figure 5: Cellulosic ethanol production in wild type and recombinant cellulolytic bacteria using $\mathrm{CMC}$ and $4 \% \mathrm{NaOH}$-treated bagasse.

increased by 93 and 53\%, respectively, [12] but the drawback of this strain was its slower growth rate than the wild type. The major limitations in all those recombinants for cellulosic ethanol production were intracellular cellulase enzyme activity, low ethanol yield, and their inability to tolerate higher percentage of ethanol. The present work focused on the cellulose hydrolysis by the microbial enzymes and fermentation of the hydrolyzed products into ethanol. The $p d c$ and $a d h$ clones of cellulolytic bacteria were screened on aldehyde indicator plates by adding acetaldehyde as a substrate for $a d h$ and ethanol for $p d c$. The $p d c$ clones had showed a PDC activity of $0.6582 \mathrm{U} / \mathrm{mL}$ and the $a d h$ II clones showed an ADH activity of $0.117 \mathrm{U} / \mathrm{mL}$.

The cellulolytic capability of insect gut-inhabiting bacteria was higher because they naturally involved in the digestion of lignocellulosic substrates which is the diet of insects. The selected cellulolytic bacteria used in the present study were isolated from various phytophagous insects so that they were efficient in cellulolytic activity. The microorganisms such as, E. chrysanthemi, E. cloacae, and $P$. mirabilis were already known for their cellulolytic activity [20,29]. Cloning of cellulase gene into ethanologenic bacteria had also already been reported [5]. The ethanol tolerance capability was studied to detect the effect of ethanol on the growth of microorganisms. E. cloacae exhibited the growth up to $4 \%(\mathrm{v} / \mathrm{v})$ supplemented ethanol and the other strains such as E. chrysanthemi and P. mirabilis were found to grow less rapidly in all ethanol concentrations, whereas there was no growth observed in 4\%. Addition of zinc in fermentation medium was found to increase the tolerance towards ethanol was reported [30] and over expression of genes involved in tryptophan biosynthesis and/or supplementation of tryptophan in the fermentation medium could also reportedly improve ethanol tolerance in yeast [31].

The ethanol production capability of the recombinant microorganisms was studied using fermentation medium under anaerobic conditions with carboxymethyl cellulose and $4 \% \mathrm{NaOH}$ pretreated bagasse as substrates. Production of high levels of PDC and ADH enzymes metabolically diverts pyruvate to ethanol as the primary product of fermentation. Expression of these enzymes for ethanol production was simultaneously increased, as evidenced by the increase in PDC activity, stronger reaction on aldehyde indicator plates (ADH II), decreased acetate, and more efficient ethanol production. As the sugar released by the cellulase action was subsequently utilized for ethanol production, as the feedback inhibition was minimum. The ethanol production of recombinant E. chrysanthemi and $P$. mirabilis using CMC was $3.5 \%$ and $3 \%$, respectively, whereas using $4 \% \mathrm{NaOH}$-treated bagasse ethanol production was less than $2 \%$. The ethanol production of recombinant $E$. chrysanthemi and P. mirabilis JV from $4 \% \mathrm{NaOH}$-pretreated bagasse has no significant difference from that of the wild type. The ethanol production of recombinant E. cloacae from $\mathrm{CMC}$ and $4 \% \mathrm{NaOH}$ treated bagasse were 4.5 and $3.5 \%$, which are higher than the other cellulolytic bacterial strains studied. This might be due to its superior ethanol tolerance, wide substrate utilization, and higher cellulolytic activity. The recombinant E. cloacae can be improved further by studying sugar catabolism and nutrient requirements to increase its ethanol production.

\section{Conclusion}

Three recombinant cellulolytic bacterial strains such as $E$. cloacae JV, E. chrysanthemi, and P. mirabilis harbouring both $p d c$ and $a d h$ II genes from $Z$. mobilis have showed an increase in cellulosic ethanol production capabilities when compared to their respective wild-type strains. Recombinant E. cloacae JV harboring both $p d c$ and $a d h$ II genes produced 4.5 and $3.5 \%$ of ethanol when $\mathrm{CMC}$ and $4 \% \mathrm{NaOH}$-treated bagasse were used as substrates, but recombinant E. chrysanthemi produced 4 and $1.5 \%$ and recombinant $P$. mirabilis produced 3.5 and $1 \%$ ethanol using the same substrates, respectively. The cellulosic ethanol production could be increased by over expressing the genes and optimizing the fermentation conditions for altering cellular metabolism for higher ethanol tolerance.

\section{Acknowledgments}

The authors acknowledge Defense Research and Development Organization (DRDO) (DLS/81/48222/LSRB-158/ BTB/2008 dated February 29th, 2008), Government of India, New Delhi, and Tamil Nadu State Council for Science and Technology (TNSCST) (TNSCST/SPS/AR/BS-34/2009-10), Chennai for their financial support.

\section{References}

[1] J. Zaldivar, J. Nielsen, and L. Olsson, "Fuel ethanol production from lignocellulose: a challenge for metabolic engineering and process integration," Applied Microbiology and Biotechnology, vol. 56, no. 1-2, pp. 17-34, 2001.

[2] K. Ohta, D. S. Beall, J. P. Mejia, K. T. Shanmugam, and L. O. Ingram, "Metabolic engineering of Klebsiella oxytoca M5A1 
for ethanol production from xylose and glucose," Applied and Environmental Microbiology, vol. 57, no. 10, pp. 2810-2815, 1991.

[3] B. E. Wood, L. P. Yomano, S. W. York, and L. O. Ingram, "Development of industrial-medium-required elimination of the 2,3-butanediol fermentation pathway to maintain ethanol yield in an ethanologenic strain of Klebsiella oxytoca," Biotechnology Progress, vol. 21, no. 5, pp. 1366-1372, 2005.

[4] H. Yanase, K. Nozaki, and K. Okamoto, "Ethanol production from cellulosic materials by genetically engineered Zymomonas mobilis," Biotechnology Letters, vol. 27, no. 4, pp. 259-263, 2005.

[5] P. T. Vasan, P. S. Piriya, D. I. G. Prabhu, and S. J. Vennison, "Cellulosic ethanol production by Zymomonas mobilis harboring an endoglucanase gene from Enterobacter cloacae," Bioresource Technology, vol. 102, no. 3, pp. 2585-2589, 2011.

[6] D. S. Beall and L. O. Ingram, "Genetic engineering of soft-rot bacteria for ethanol production from lignocellulose," Journal of Industrial Microbiology, vol. 11, no. 3, pp. 151-155, 1993.

[7] C. Wills, P. Kratofil, D. Londo, and T. Martin, "Characterization of the two alcohol dehydrogenases of Zymomonas mobilis," Archives of Biochemistry and Biophysics, vol. 210, no. 2, pp. 775-785, 1981.

[8] A. D. Neale, R. K. Scopes, J. M. Kelly, and R. E. Wettenhall, "The two alcohol dehydrogenases of Zymomonas mobilis: purification by differential dye ligand chromatography, molecular characterisation and physiological roles," European Journal of Biochemistry, vol. 154, no. 1, pp. 119-124, 1986.

[9] L. O. Ingram, T. Conway, D. P. Clark, G. W. Sewell, and J. F. Preston, "Genetic engineering of ethanol production in Escherichia coli," Applied and Environmental Microbiology, vol. 53, no. 10, pp. 2420-2425, 1987.

[10] A. T. Lee, A. G. Malgorzata, P. Y. Lorraine, L. O. Ingram, and A. M. Julie, "Construction and expression of an ethanol production operon in Gram-positive bacteria," Microbiology, vol. 151, no. 12, pp. 4023-4031, 2005.

[11] J. S. Tolan and R. K. Finn, "Fermentation of D-Xylose and Larabinose to ethanol by Erwinia chrysanthemi," Applied and Environmental Microbiology, vol. 53, pp. 2033-2038, 1987.

[12] E. Guedon, M. Desvaux, and H. Petitdemange, "Improvement of cellulolytic properties of Clostridium cellulolyticum by metabolic engineering," Applied and Environmental Microbiology, vol. 68, no. 1, pp. 53-58, 2002.

[13] J. Sambrook and D. W. Russel, Molecular Cloning: A Laboratory Manual, Cold Spring Harbor Laboratory, Cold Spring Harbor, NY, USA, 3rd edition, 2003.

[14] H. C. Bimboim and J. Doly, "A rapid alkaline extraction procedure for screening recombinant plasmid DNA," Nucleic Acids Research, vol. 7, no. 6, pp. 1513-1523, 1979.

[15] R. D. Lillie, H. J. Conn's Biological Stains, The Williams \& Wilkins, Baltimore, Md, USA, 9th edition, 1977.

[16] P. Gunasekaran, T. Karunakaran, B. Cami, A. G. Mukundan, L. Preziosi, and J. Baratti, "Cloning and sequencing of the sacA gene: characterization of a sucrase from Zymomonas mobilis," Journal of Bacteriology, vol. 172, no. 12, pp. 6727-6735, 1990.

[17] A. D. Gounaris, I. Turkenkopf, S. Buckwald, and A. Young, "Pyruvate decarboxylase. I. Protein dissociation into subunits under conditions in which thiamine pyrophosphate is released," The Journal of Biological Chemistry, vol. 246, no. 5, pp. 1302-1309, 1971.

[18] J. Fibla, S. Atrian, and R. G. Duarte, "Evidence of serineprotease activity closely associated with Drosophila alcohol dehydrogenase," European Journal of Biochemistry, vol. 211, no. 1-2, pp. 357-365, 1993.
[19] Y. Zhou, W. X. Ye, Y. Zhou, C. G. Zhu, M. Sun, and Z. N. Yu, "Ethanol tolerance, yield of melanin, swarming motility and growth are correlated with the expression levels of aiiA gene in Bacillus thuringiensis," Enzyme and Microbial Technology, vol. 38, no. 7, pp. 967-974, 2006.

[20] B. L. Fernandes and S. O. P. Da Costa, "High efficiency of transformation of Proteus mirabilis with a pUC19 derivative vector directs the expression and secretion of the Bacillus subtilis $\alpha$-amylase gene," Journal of Microbiological Methods, vol. 26, no. 1-2, pp. 147-150, 1996.

[21] S. J. Vennison, Laboratory Manual for Genetic Engineering, PHI Publications, New Delhi, India, 2009.

[22] J. Jeffers, Preparation of Ethanol by Fermentation, Ouachita Baptist University, 2000.

[23] S. Fogel, R. L. Lancione, and A. E. Sewall, "Enhanced biodegradation of methoxychlor in soil under sequential environmental conditions," Applied and Environmental Microbiology, vol. 44, no. 1, pp. 113-120, 1982.

[24] N. Kiransree, M. Sridhar, and L. V. Rao, "Characterisation of thermotolerant, ethanol tolerant fermentative Saccharomyces cerevisiae for ethanol production," Bioprocess Engineering, vol. 22, no. 3, pp. 243-246, 2000.

[25] A. K. Hilaly, M. N. Karim, and J. C. Linden, "Use of an Extended Kalman Filter and development of an automated system for xylose fermentation by a recombinant Escherichia coli," Journal of Industrial Microbiology, vol. 13, no. 2, pp. 8389, 1994.

[26] H. G. Lawford and J. D. Rousseau, "Factors contributing to the loss of ethanologenicity of Escherichia coli B recombinants pLOI297 and KO11," Applied Biochemistry and Biotechnology - Part A, vol. 57-58, pp. 293-305, 1996.

[27] J. B. Doran, J. Cripe, M. Sutton, and B. Foster, "Fermentations of pectin-rich biomass with recombinant bacteria to produce fuel ethanol," Applied Biochemistry and Biotechnology - Part A, vol. 84-86, pp. 141-152, 2000.

[28] V. Senthilkumar and P. Gunasekaran, "Bioethanol production from cellulosic substrates: engineered bacteria and process integration challenges," Journal of Scientific and Industrial Research, vol. 64, no. 11, pp. 845-853, 2005.

[29] A. P. Anand, S. J. Vennison, S. G. Sankar et al., "Digestion of cellulose, pectin, xylan and starch by the symbiotic gut bacteria in the intestine ofBombyx mori," Insect Science, vol. 10, no. 107, pp. 1-20, 2009.

[30] X. Q. Zhao, C. Xue, X. M. Ge, W. J. Yuan, J. Y. Wang, and F. W. Bai, "Impact of zinc supplementation on the improvement of ethanol tolerance and yield of self-flocculating yeast in continuous ethanol fermentation," Journal of Biotechnology, vol. 139, no. 1, pp. 55-60, 2009.

[31] H. Yazawa, H. Iwahashi, and H. Uemura, "Disruption of URA7 and GAL6 improves the ethanol tolerance and fermentation capacity of Saccharomyces cerevisiae," Yeast, vol. 24, no. 7, pp. 551-560, 2007. 

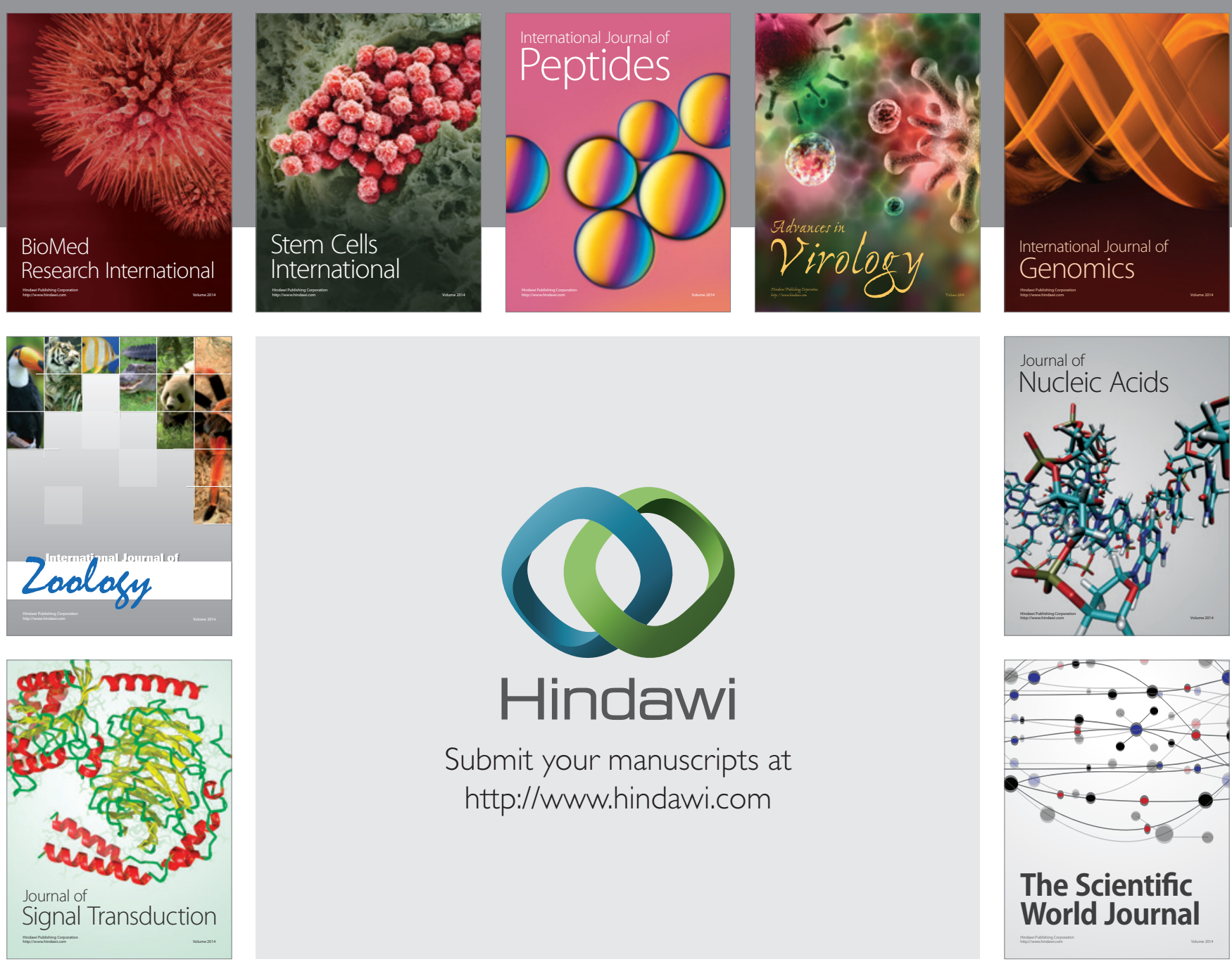

Submit your manuscripts at

http://www.hindawi.com
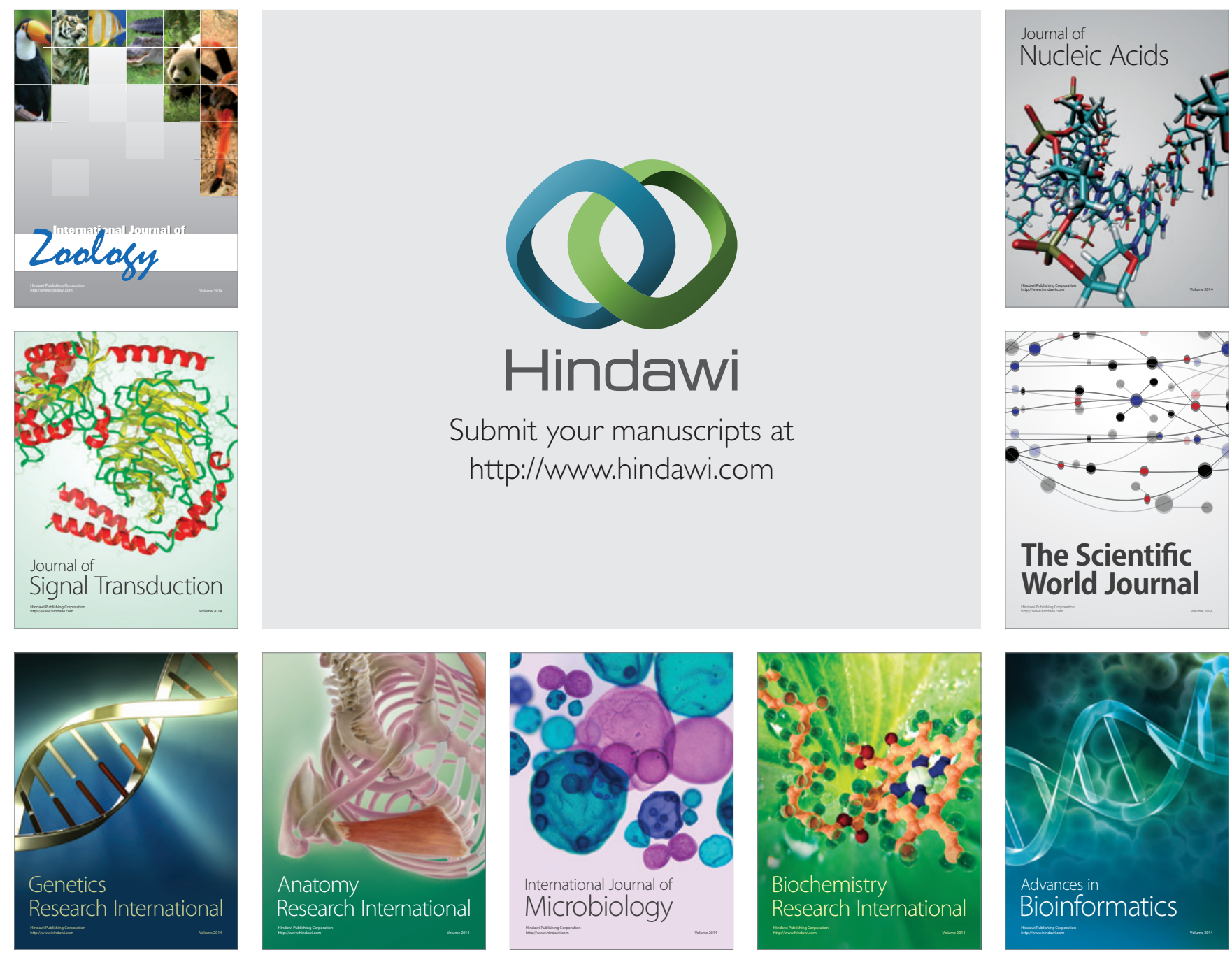

The Scientific World Journal
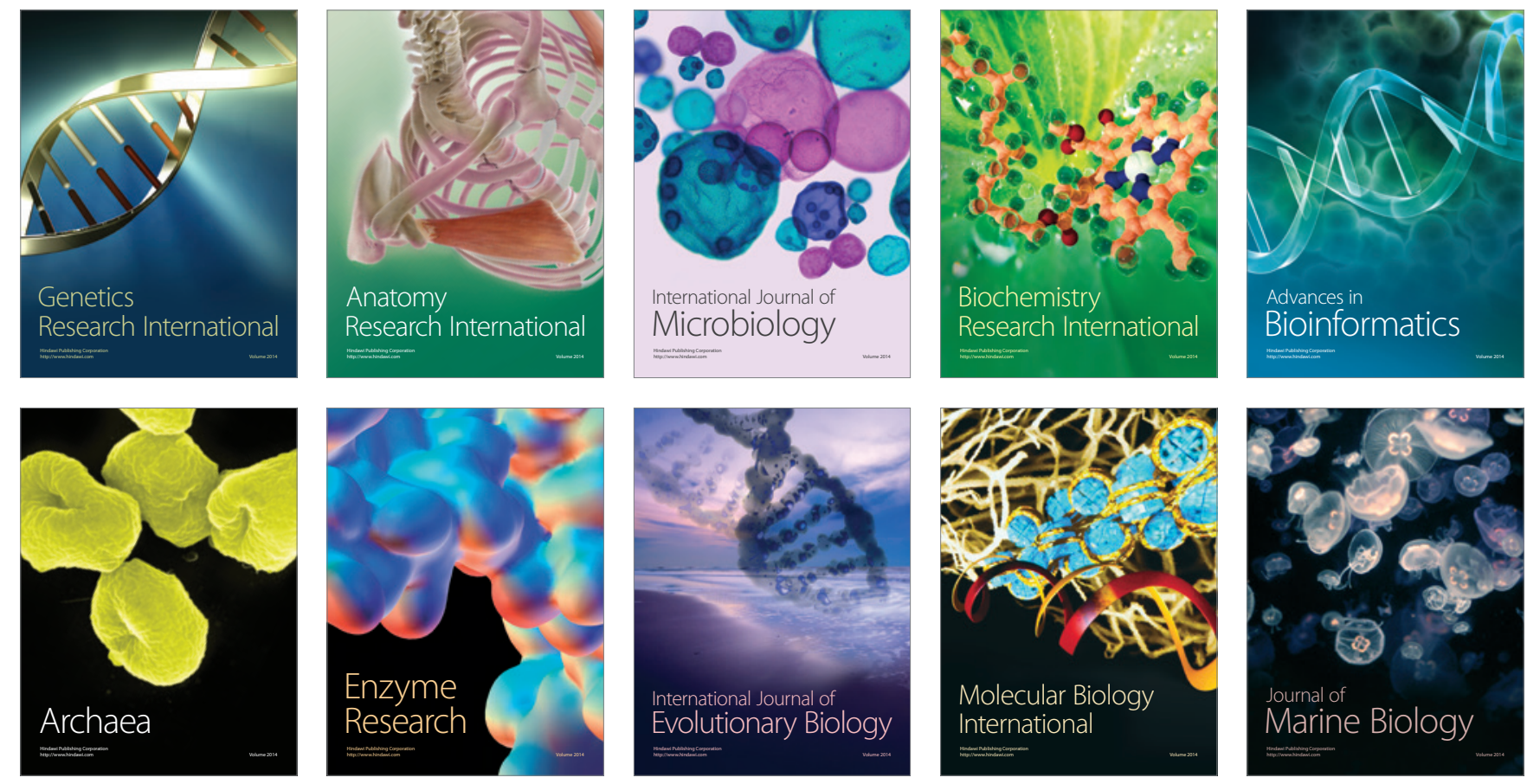